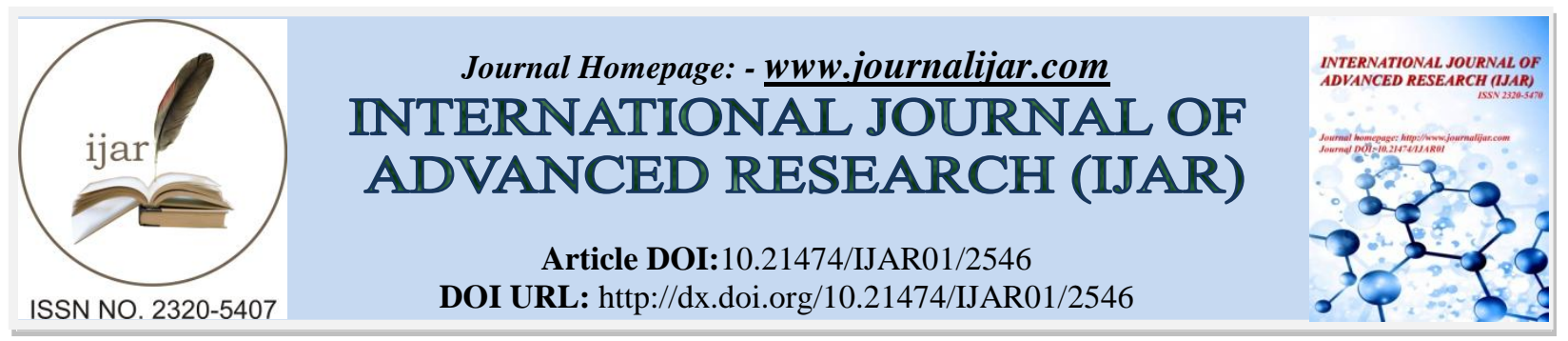

\title{
RESEARCH ARTICLE \\ Prevalence, risk factors, maternal and fetal outcome of PROM in maternity and child hospital Makkah KSA.
}

\section{Albager Mahdi ${ }^{1}$, Faisal Alrefaei ${ }^{2}$, Majdi Alzahrani ${ }^{3}$, Maher Alhafithi ${ }^{3}$, Ahmad Rashed $^{3}$, Abdullatif Binjabi ${ }^{3}$ and Ahmed Idris ${ }^{3 .}$}

1- Assistant Professor at Department of Obstetrics and Gynecology, Faculty of Medicine, Umm Al-Qura University, Makkah, Saudi Arabia.

2- Medical Intern, Faculty of Medicine, Umm Al-Qura University, Makkah, Saudi Arabia.

3- Medical Student, Faculty of Medicine, Umm Al-Qura University, Makkah, Saudi Arabia.

\section{Manuscript Info}

Manuscript History

Received: 25 October 2016

Final Accepted: 23 November 2016

Published: December 2016

\section{Abstract}

Copy Right, IJAR, 2016,. All rights reserved.

\section{Introduction:-}

Premature rupture of membranes (PROM) refers to membrane rupture before the onset of uterine contractions (also known as prelabor rupture of membranes); preterm PROM (PPROM) refers to PROM before $37^{\text {th }}$ weeks of gestation.Preterm premature rupture of membranes (PPROM) occurs in 3 percent of pregnancies and is responsible for, or associated with, approximately one-third of preterm births ${ }^{[1]}$ while At term, PROM complicates about 8 $10 \%$ of all pregnancies.Maternal physiologic, genetic, and environmental factors likely predispose to development of preterm premature rupture of membranes (PPROM) in many cases. These risk factors are similar to those for preterm labor, but most patients have no identifiable risk factors. A history of PPROM in a previous pregnancy, genital tract infection, antepartum bleeding, and cigarette smoking have a particularly strong association with PPROM $^{[2]}$.

The classic clinical presentation of PPROM is a sudden "gush" of clear or pale yellow fluid from the vagina. However, many women describe intermittent or constant leaking of small amounts of fluid or just a sensation of wetness within the vagina or on the perineum. Findings on physical examination are observation of amniotic fluid coming out of the cervical canal or pooling in the vaginal fornix which is pathognomonic of PPROM. If amniotic fluid is not immediately visible, the woman can be asked to push on her fundus, Valsalva, or cough to provoke leakage of amniotic fluid from the cervical os.For patients who are not in active labor, examination of the cervix and vagina should be performed using a sterile speculum. Digital examination should be avoided because it may decrease the latency period (i.e. time from rupture of membranes to delivery) and increase the risk of intrauterine infection ${ }^{[4,3]}$.

\section{Diagnosis:-}

The diagnosis of preterm premature rupture of membranes (PPROM) is clinical, and is generally based on visualization of amniotic fluid in the vagina of a woman who presents with a history of leaking fluid. Laboratory tests can be used to confirm the clinical diagnosis when it is uncertain which are:ferning test and nitrazine test for the fluid taken from vaginal vault and ultrasound confirmation of oligohydramnios. 


\section{Management:-}

The management of pregnancies complicated by PPROM is based upon consideration of several factors, which are assessed upon presentation which include: Gestational age, presence or absence of maternal/fetal infection, presence or absence of labor, fetal presentation, fetal well-being, fetal lung maturity, cervical status (by visual inspection) and availability of neonatal intensive care.

In the absence of these complications, PPROM is treated expectantly and no intervention to effect delivery prior to 34 weeks. The optimal time for intervention varies among institutions and depends on the balance between morbidity related to prematurity and morbidity related to complications of PPROM. The American College of Obstetricians and Gynecologists (ACOG) suggests delivery for all patients' $\geq 34$ weeks of gestation ${ }^{\text {[5] }}$

\section{Objectives:-}

To study the prevalence of preterm premature rupture of the membranes (PPROM) between 26-36 week gestation with identify the risk factor, outcomes and of complication of the pregnant women and the neonates.

\section{Methods:-}

A retrospective study of 380071 pregnancies registered and managed in the Department of Obstetrics and Gynecology, King Abdullah Medical City, Makkah, Kingdom of Saudi Arabia (KSA) from October 2014 to January 2016.

\section{Inclusion criteria:-}

All patients with documented evidence of PPROM between 26-36 weeks gestation were included in the study.

\section{Results:-}

Four hundred and twenty-nine cases of PPROM (0.11\%) were registered and treated expectantly out of 380071 total pregnancies registered during the study period. Maternal age from 30 to 34 years were (29.1\%), from 25 to 29 years were $(25.6 \%)$ and from 20 to 24 years $(19.3 \%)$.

Gestational age between 32 -36 weeks represents the majority of the cases $(92.6 \%)$ while the gestational age between $24-31$ weeks were $(3.8 \%)$ and $19-23$ weeks were $(3.6 \%)$.

Majority of the patients had parity between 1 and 4 women (65.2\%), whilenulliparous ladies were (17.7\%).

The most common presenting symptoms was painless leakage of fluid is main complain (76.4\%), followed by abdominal pain $(16.1 \%)$ and fever in $(6.3 \%)$.

Antenatal maternal risk factors include previous cesarean section (27\%), gestational diabetes (8.4\%), APH (4.4\%) and the rest were hypertension, DM, hypothyroidism and anemia.

Maternal complications include first- degree perineal laceration (12.8\%), chorioamnionitis $(0.2 \%)$, postpartum hemorrhage $(1.9 \%)$, abruptio-placentae $(0.2 \%)$ and septicemia $(0.5 \%)$.

The prenatal survival rate was $94.8 \%$ whereas neonatal outcomes included neonatal mortality $(5.1 \%)$, fetal distress $(22.6 \%)$, intrauterine growth restriction $(0.7 \%)$, and gastroschisis $(0.2 \%)$. $(54.8 \%)$ of preterm deliveries were spontaneous, $(41.7 \%)$ cesarean section and $(3.6 \%)$ dilation and curettage. The indications for cesarean section: previous cesarean section (27\%), abnormal presentation (5.4\%) macrosomia (2.3\%), multiple gestations (1.4\%).

Figure 1:-Distribution of the cases according maternal age. 


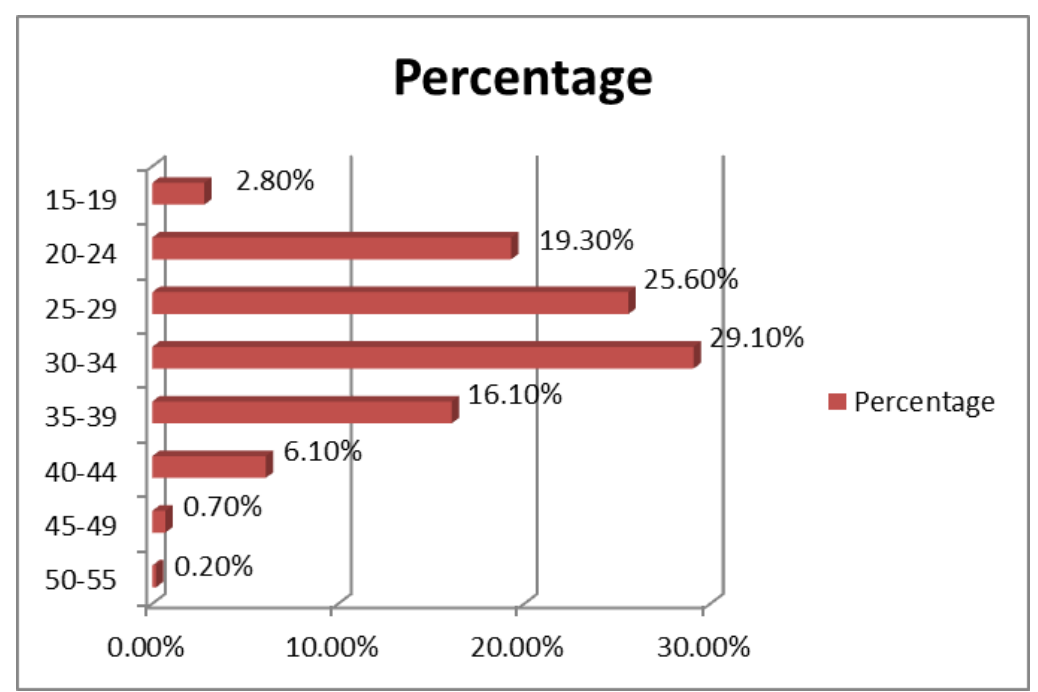

Figure 2:-Distribution of the cases according to gestational age:

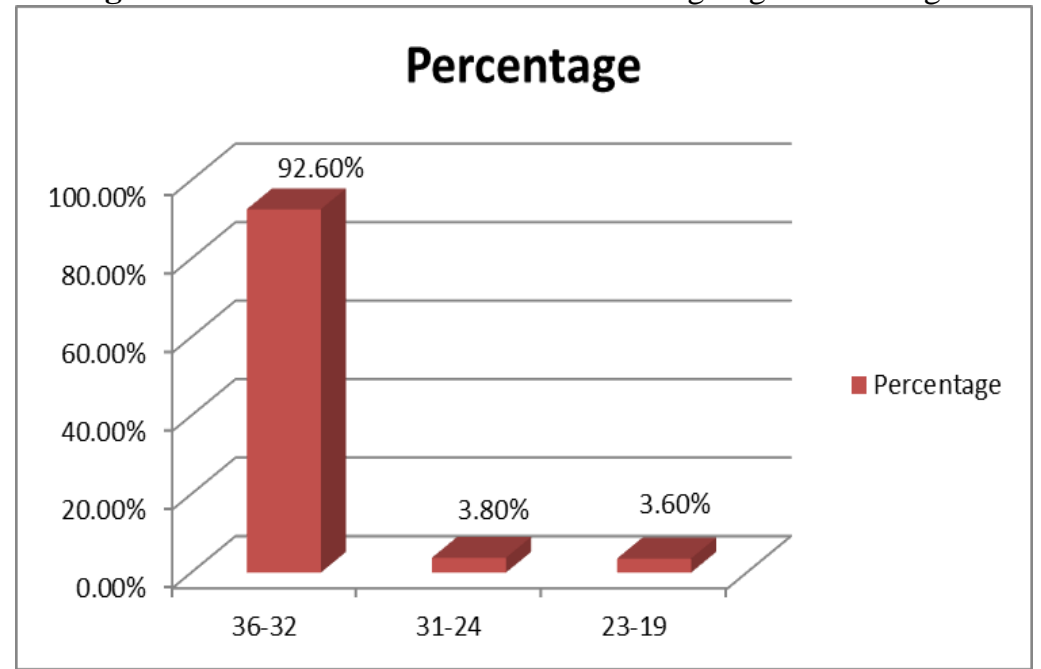

Figure 3:-Distribution of the cases according to parity:

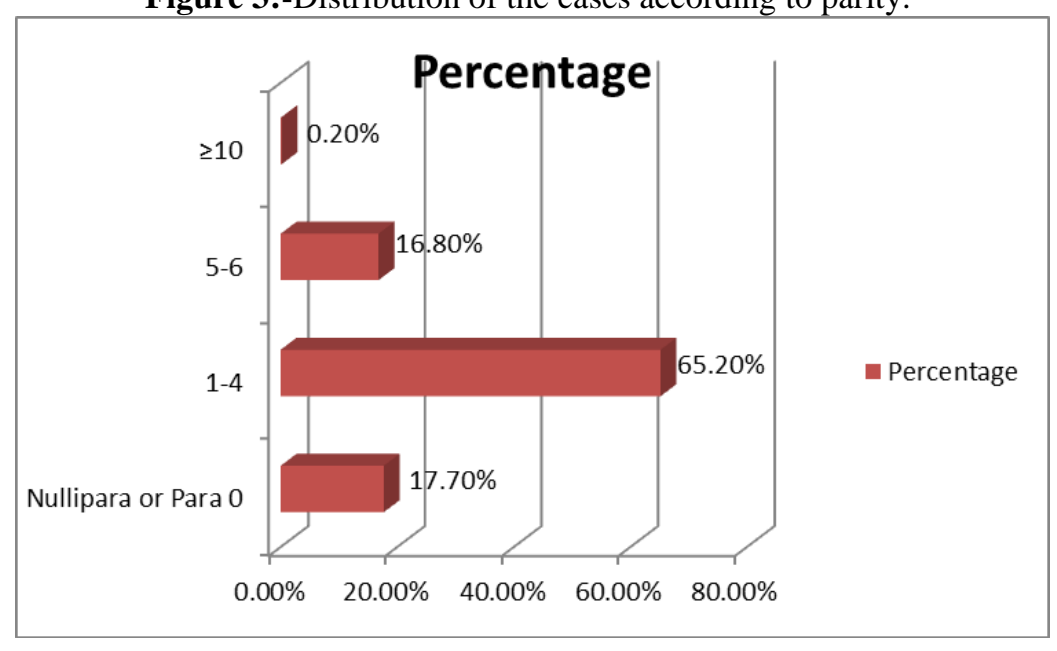

Figure 4:-Maternal complications: 


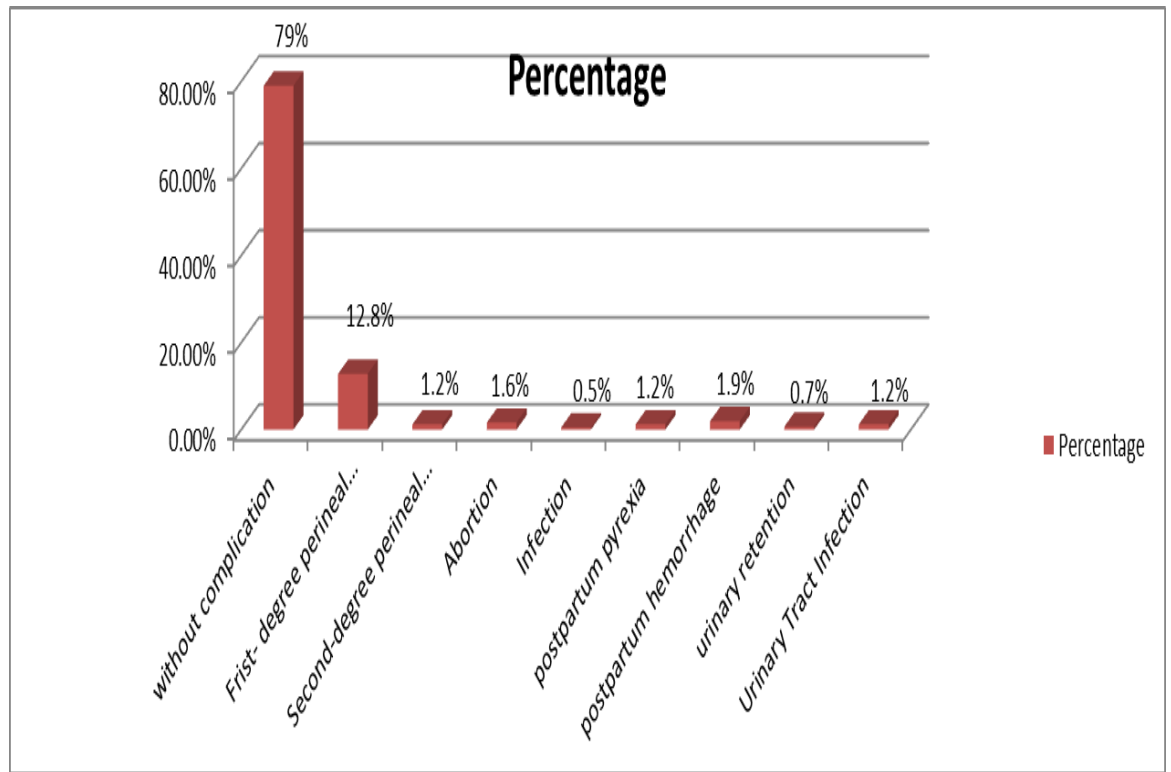

Table 1:-Distribution of the cases according to the clinical presentation:

\begin{tabular}{|l|l|l|}
\hline Presenting complains & Frequency & Percentage \\
\hline Leakage of fluid & 328 & $76.4 \%$ \\
\hline Abdominal pain & 69 & $16.1 \%$ \\
\hline Fever & 27 & $6.3 \%$ \\
\hline Bleeding & 3 & $0.7 \%$ \\
\hline
\end{tabular}

Table 2:-The associated risk factors.

\begin{tabular}{|l|l|l|}
\hline $\begin{array}{l}\text { Antenatal complication } \\
\text { (risk factor) }\end{array}$ & Frequency & Percentage \\
\hline Without complication & 144 & $33.6 \%$ \\
\hline Abnormal presentation & 23 & $5.4 \%$ \\
\hline Vaginal bleeding & 19 & $4.4 \%$ \\
\hline Anemia & 8 & $1.9 \%$ \\
\hline Asthma & 9 & $2.1 \%$ \\
\hline Diabetes Mellitus & 36 & $8.4 \%$ \\
\hline Hypertension & 15 & $3.5 \%$ \\
\hline History of mastectomy & 1 & $0.2 \%$ \\
\hline Hypothyroidism & 7 & $1.6 \%$ \\
\hline Infection & 6 & $1.4 \%$ \\
\hline IUGR & 1 & $0.2 \%$ \\
\hline Multiple gestation & 6 & $1.4 \%$ \\
\hline Oligohydramnios & 6 & $1.4 \%$ \\
\hline Ovarian cysts & 2 & $0.5 \%$ \\
\hline Pre-eclamptic & 11 & $2.6 \%$ \\
\hline Ployhydramnios & 3 & $0.7 \%$ \\
\hline Previous c/s (uterine scar) & 116 & $27.0 \%$ \\
\hline Previous intrauterine death & 3 & $0.7 \%$ \\
\hline Passive smoker & 3 & $0.7 \%$ \\
\hline Macrosomia & 10 & $2.3 \%$ \\
\hline
\end{tabular}

Tables 2,3 and 4:-represent the fetal outcome, fetal complications and mode of delivery. 


\begin{tabular}{|l|l|l|}
\hline fetal outcome & frequency & Percentage \\
\hline Single live birth & 397 & $92.5 \%$ \\
\hline twins, both live born & 10 & $2.3 \%$ \\
\hline Stillbirth & 22 & $5.1 \%$ \\
\hline
\end{tabular}

\begin{tabular}{|l|l|l|}
\hline fetal complication & frequency & Percentage \\
\hline without complication & 318 & $74.1 \%$ \\
\hline Bradycardia & 5 & $1.2 \%$ \\
\hline cord compression & 4 & $0.9 \%$ \\
\hline Dystocia & 1 & $0.2 \%$ \\
\hline fetal distress & 97 & $22.6 \%$ \\
\hline Gastroschisis & 1 & $0.2 \%$ \\
\hline IUGR & 3 & $0.7 \%$ \\
\hline
\end{tabular}

\begin{tabular}{|l|l|l|}
\hline mode of delivery & frequency & Percentage \\
\hline SVD & 235 & $54.8 \%$ \\
\hline C/S & 179 & $41.70 \%$ \\
\hline D\&C & 15 & $3.6 \%$ \\
\hline
\end{tabular}

\section{Discussion:-}

The incidence of preterm premature rupture of membranes of all hospital admission in this study is $6.2 \%$ in comparison to a study held in Riyadh in which the incidence was only was $0.6 \%$ [6] , preterm delivery occurs in $12.3 \%$ of all births in the United States at 2003 which show slight increase compare in 1992 which was 10.7\% [7] . Our study showed a peak incidence of PPROM at 30-34 years (29.1\%) (Mean age is 32). However, in Libya was 2130 years $(61 \%)$ [6]. and in UK 19-39 (mean age is 29 years old) [8]. Our study showed higher incidence of PPROM in ladies with Parity between 1-4 women (65.2\%)unlike the international and regional studies which showed a predominance of nulliparous, (UK was $43.9 \%$ nulliparous [8] and in Libya was nulliparous in 52\% [9]).

The distribution of gestational age among this study show 32-36 was $92.6 \%$ which is the most common, 24-31 was $3.8 \%$ and 19-23 was 3.6\%, compare with study done among of 2241 women randomized in the original study. 275 (18\%) were delivered following early PPROM at less than 25.0 weeks' gestation, at a mean gestational age of $23.7 \pm$ 1.2 (range, 15.1-24.9) weeks' gestation. The remaining 1256 (82\%) had later PPROM, at a mean gestational age of $28.7 \pm 2.2$ (range, 25.0-31.9) weeks' gestation [10].

The mode of delivery in this study shows SVD of $54.8 \%$ while in UK was $53 \%$ however in Libya was $62 \%$. The abortion in this study was $1.6 \%$ and in UK was 3.9\% and in Libya 5\% [6], [8]. On other hand caesarian section was done with $41.70 \%$ high rate in compare with study was done in Rockford Memorial hospital shown (31.5\%) neonates were delivered by cesarean section [10]. Also, another study in Ayub Medical College, Abbottabadshown caesarean section rate was $14 \%$ [11] . Dilation and curettage in this study was 3.6\% while in previous study dilation and curettage $10.9 \%$ [12]. While convulsion there was no data available in relation with PPROM.

The associated symptoms that shown a leakage of fluid $76.4 \%$, abdominal pain $16.1 \%$, fever $6.3 \%$, stained blood $0.7 \%$ and convolution $0.5 \%$. In previous study the classic clinical presentation of PPROM is a sudden "gush" of clear or pale yellow fluid from the vagina. However, many women describe intermittent or constant leaking of small amounts of fluid or just a sensation of wetness within the vagina or on the perineum [11]. On other hand fever present in case control study which was $44.7 \%$ [13] , the abdominal pain it was unspecific may due to infection ; chorioamnionitis, UTI , septicemia or any complication of pprom ; placental abruption, abortion, or could be related to hemorrhage as postpartum hemorrhage as hemodynamic instability (tachycardia, hypotension, or shock) [14] .In another study the associated stained blood in related to PPROM in $1^{\text {st }}$ trimester was $37.4 \%$ while in $2^{\text {nd }}$ trimester was $15 \%[15]$.

\section{The antenatal complication in this study, we found as follows;}


Abnormal presentation which represent $5.4 \%$, in previous study abnormal presentation represent twenty-eight $(38.4 \%)$ fetuses were in cephalic position and 45 (61.6\%) fetuses were in breech presentation among pregnant patients who had preterm premature rapture of membranes [10].

Antepartum hemorrhage represent $4.4 \%$, while in previous study done in Libya was $1 \%$ however in UK was $51 \%$ [6.8].

Gestational diabetes mellitus which represent 4.2\%, in previous study in United kingdom was $1.8 \%$ [8], a retrospective cohort study was performed based on 111563 pregnancies delivered between 1991 through 1997 in 39 hospitals in northern and central Alberta, Canada, shown the prevalence of gestational diabetes mellitus was $2.5 \%$, mothers with GDM were at increased risk of presenting with pre-eclampsia, premature rupture of membranes, cesarean section, and preterm delivery [16]. However macrosomia which represent in this current study $2.3 \%$, the frequency of macrosomia reported from previous studies has varied from $1.8 \%$ at Kaiser - Permanente medical center in Los Angeles , California in 1974 to 1975, to 0.18\% in Barigkok, Thailand in 1972, to 1.77 in New York city in 1950 [110-111-112]. The maternal risk factor for having macrocosmic infant include ; high body mass index , maternal diabetes, male infant, previous macrocosmic infant and excessive weight gain during pregnancy [17] .

Maternal hypertensions which represent $3.5 \%$, a case control study founded shown the hypertension was $18.8 \%$ compare with control was $6.6 \%$ [12].

Asthmatic patient represent $2.1 \%$, in previous case control study in Massachusetts General Hospital (MGH) between September 2011 and June 2012 shown the frequency of asthma was $20 \%$ compare with the control was $19 \%$ [15].

Hypothyroidism represent in this study $1.6 \%$, in study was done in the United Kingdom the hypothyroidism was $1.3 \%$ among pregnant women with PPROM [8].

The infection rate in the current study represent $1.4 \%$, chorioamnionitis $0.2 \%$, septicemia $0.5 \%$ and urinary tract infection $1.2 \%$, in previous studies the risk of infection is significant following preterm PROM. Five (6.8\%) patients had endomyometritis, one incident of which resulted in maternal sepsis. There was no long-term maternal sequela. Also study reported the rates of chorioamnionitis and urinary infection were found significantly higher in the PPROM group compared with women without PPROM (16.5 vs. 2.7\%; 5.1 vs. 3.3\%, respectively) $(\mathrm{P}<0.001)$. And the rate of endometritis and bacteremia in the postpartum period were significantly higher in women with PPROM compared with controls 2.8 vs. $1.4 \%,(\mathrm{P}=0.003)$ and 9.4 vs. 5\%, $(\mathrm{P}=0.001)$. Also a study finding revealed the most common maternal complication to be infection. Out of 44 women with PPROM, infection was observed in 20 (45\%) patients. A population based case control study used maternally liked Washington State from 1984 to 1993 reported sepsis among women with PPROM with 4.1\% [10, 18, 19, and 20].

Intrauterine growth restriction represent $0.7 \%$, in previous studies shown the neonatal and perinatal outcome of the babies ,total $53(62.3 \%)$ babies born to mothers with PPROM were low birth weight which include $10(11.76 \%)$ babies of extremely low birth and $30(35.29 \%)$ babies of very low birth weight [13]. Another study shown the median birth weightof included neonates was $1150 \mathrm{~g}$ (range: 850-2400 g; interquartile range: $950-1600 \mathrm{~g}$ ) [21]. Another study occurring between 1988 and 1997 at the Soroka University Medical Center in Israel reported PPROM was associated with a significantly lower gestational age (24-32 weeks) and birth weight $(<2500 \mathrm{~g})$ than those with intact membranes [18].

Multiple gestations in this current study shown $1.4 \%$, a previous study found that preterm premature rupture of membranes occurs more frequently in twin than singleton gestations $(7.4 \% \mathrm{v} / \mathrm{s} 3.7 \%, \mathrm{p}<0.001$, odds ratio 2.1$)$. Mid trimester premature rupture of membranes (<26 weeks' gestation) complicated $1.37 \%$ of twin gestations $(18.2 \%$ of those with preterm premature rupture of membranes) versus $0.52 \%$ of singleton gestations ( $\mathrm{p}<0.001$, odds ratio 2.71) [20].

Oligohydramnios which represent $1.4 \%$ and study reported that fifty to seventy percent of women with PPROM have low amniotic fluid volume on initial sonography [23]. 
Preeclampsia represents 2.6\%, and study done in St Michael's Hospital, Bristol, UK. Shown the percentage of preeclampsia among 35 gestation age was $23.2 \%$ [8].

Ployhydramnios represent $0.7 \%$, previous study in Benghazi, Libya in 2015, shown the polyhydromnios was $1 \%$ [6].

Placental abruption in the current study was $(0.2 \%)$, a previous study reported placental abruption was 29 patient $10.6 \%$ in early PPROM, while in late PPROM 99 patient 7.9\% [9]. Also another study in King Khalid University hospital, Riyadh, Kingdom of Saudi Arabia shown placental abruption (4\%) [5].

Intrauterine fetal death which was $0.7 \%$, a prospective study reported that, the principal causes of IUFD were infections, including premature rupture of the membranes (15\%) among sixty sex cases of intrauterine fetal death [24].

Smoking shown $0.7 \%$ smoker during pregnancy, however a previous study among 1129 patients reported the use of tobacco and 3076 denied using tobacco. Among all patients admitting to the use of tobacco during this pregnancy (n = 1129), 261 (23.1\%), no significant association was found between the incidence of PPROM and smoking [118]. A population based, case control study used maternally liked Washington State from 1984 to 1993 reported smoking among women with PPROM with 27.8 \% [20]. There was no evidence or data related ovarian cyst with PPROM.

The fetal outcome in this current study showed a single live birth $92.5 \%$, twin live birth $2.3 \%$ and stillbirth $5.1 \%$. Previous studies of fetal outcomes among the 73 fetuses that were delivered, 22 (30.1\%) were stillborn, and 13 $(17.8 \%)$ died within 24 hours of delivery, the survival rate was $52.1 \%$ [10].

In laboratory investigation $\mathrm{WBC}$ in current study was high in $24.50 \%$, normal $\mathrm{WBC}$ was $24.50 \%$. compere with other case control study sown the serum values (Mean Standard Deviation) between women with and without preterm premature rupture of membranes increase the white blood cell count in the case population which was 14.34 ( 4.4 ) compared with the controls 10.35 (2.0) [103]. 8 out of 429 patients diagnosis with anemia in this study with $1.9 \%$ in compare with case control study shown the maternal hemoglobin and hematocrit were significantly lower in the women with preterm PROM compared with the control population .The mean hemoglobin for women with preterm PROM was $113.5 \mathrm{~g} / \mathrm{L}$ (10.8) compared with $122.4 \mathrm{~g} / \mathrm{L}$ (8.9) in women without preterm PROM [25]. Urine culture there was no obvious study for urine culture in relation of PPROM.

Maternal complication, a three hundred and thirty-nine out of four hundred and twenty-nine cases of PPROM was uncomplicated, the complication include ; first- degree perineal laceration $12.8 \%$, Second-degree perineal laceration $1.2 \%$, abortion $1.6 \%$, postpartum pyrexia $1.2 \%$, postpartum hemorrhage $1.9 \%$, infection $0.5 \%$, urinary tract infection $1.2 \%$ and urinary retention $0.7 \%$. In comparison with previous studies, in The Netherlands a study was found that report 776 women were asked to participate in trial, of which 536 women (69\%) gave informed consent. A total of 268 women were randomized to IOL (induction of labor group) and 268 to EM (expectant management group), the maternal outcome for both group shown first degree laceration in IOL group with $19 \%$, EM with $20 \%$, the second degree of lacerationfor IOL group $10 \%$, EM group $13 \%$ [23] .

A case control study shown the percentage of abortion $31.2 \%$ compare with control with $21.7 \%$ [12].

Also case control study reported the postpartum hemorrhage represent $8.1 \%$ in compare with the control $4.4 \%$ [25].

Infection and urinary tract infection; discussed above. Postpartum pyrexia and urinary retention there was no available data in relation with PPROM.

The fetal complication among this study as explained in results that show 318 out of 429 they don't have any complication with percentage $74.1 \%$, the complication that include ; cord compression $0.9 \%$, bradycardia $1.2 \%$, dystocia $0.2 \%$, fetal distress $22.6 \%$, gastroschisis $0.2 \%$, IUGR $0.7 \%$. In previous study fetal distress in King Khalid University hospital, Riyadh, Kingdom of Saudi Arabia was 15.9\% [95], also another study reported umbilical cord prolapsed $7(30.4 \%)$ [10]. in previous study reported that in all 15 women who underwent spontaneous vertex delivery but the infant experienced shoulder dystocia [26].

The incidence of gastroschisis is similar in male and female fetuses, higher in singleton pregnancies than in twin 
pregnancies. This is likely related to lifestyle factors that characterize this population (cigarette smoking, use of recreational drugs, alcohol consumption, low body mass index, increased frequency of genitourinary infection. Developed and developing countries worldwide have reported an increasing incidence of gastroschisis. In a study of data from 25 population-based registries in 15 European countries, maternal age-standardized incidence of gastroschisis increased almost fourfold, from 0.54 per 10,000 births between 1980 and 1984 to 2.12 per 10,000 births between 2000 and 2002. Similarly, data from 14 US states showed a 30 percent increase in incidence from 1995-2005 to 2006-2012 (from 3.6/10,000 to 4.9/10,000); the increase varied but was significant across all categories of maternal age and race/ethnicity [27]. IUGR; discussed above.

The indications for cesarean section : previous cesarean section (27\%), abnormal presentation (5.4\%) macrosomia (2.3\%), multiple gestation (1.4\%). In a research was done in Benghazi, Libya that reported the indication of cesarean section was previous caesarian section $3.6 \%$, abnormal presentation $7.2 \%$, big size baby $3.6 \%$ [6].

\section{Conclusions:-}

The data from this study show the incidence of PPROM in KSA is low, more than 50\% of preterm births follow spontaneous preterm labor, and the previous cesarean section is most common risk factor and common in multiparty, 30 years old and 36 weeks of gestational age.

\section{References:-}

1. Mercer BM. Preterm premature rupture of the membranes: current approaches to evaluation and management. ObstetGynecolClin North Am 2005; 32:411.

2. Harger JH, Hsing AW, Tuomala RE, et al. Risk factors for preterm premature rupture of fetal membranes: a multicenter case-control study. Am J ObstetGynecol 1990; 163:130.

3. Alexander JM, Mercer BM, Miodovnik M, et al. The impact of digital cervical examination on expectantly managed preterm rupture of membranes. Am J ObstetGynecol 2000; 183:1003.

4. Imseis HM, Trout WC, Gabbe SG. The microbiologic effect of digital cervical examination. Am J ObstetGynecol 1999; 180:578.

5. American College of Obstetricians and Gynecologists. Practice Bulletin No. 160: Premature Rupture of Membranes. ObstetGynecol 2016; $127:$ e39.

6. Tariq Y. Khashoggi premature rupture of membrane in Saudi Arabia :Outcome of pregnancies with preterm premature rupture of membranes. Saudi Med J. 2004 Dec;25(12):1957-61.

7. ACOG Committee on Practice Bulletins-Obstetrics. ACOG Practice Bulletin No. 80: premature rupture of membranes. Clinical management guidelines for obstetrician-gynecologists. ObstetGynecol 2007;109:10071019

8. Wei Yuan, Anne M Duffner, Lina Chen, Linda P Hunt, Susan M Sellers and Andrés López Bernal. Analysis of preterm deliveries below 35 weeks' gestation in a tertiary referral hospital in the UK. A case-control survey. Biomedicine journals. 28 April 2010. Available: http://bmcresnotes.biomedcentral.com/articles/10.1186/17560500-3-119 [assessed 19-9-2016].

9. Milad M. M. Gahwagi, Musa O. Busarira, Mona Atia. Premature Rupture of Membranes Characteristics, Determinants, and Outcomes of in Benghazi, Libya. Open Journal of Obstetrics and Gynecology. Vol.05 No.09 (2015).

10. Tracy Ann Manuck and Michael Walter Varner. Neonatal and early childhood outcomes following early vs later preterm premature rupture of membranes. Am J Obstet Gynecol. 2014 Sep; 211(3): 308.e1-308.e6. Available : ( 7 September 2016) on : http://www.ncbi.nlm.nih.gov/pmc/articles/PMC4270010/

11. Shehla Noor, Ali FawwadNazar, Rubina Bashir, Ruqqia Sultana .PREVALANCE OF PPROM AND ITS OUTCOME. Journal of Ayub Medical College, Abbottabad: JAMC . October2007.Availablehttps://www.researchgate.net/profile/Shehla_Noor/publication/23162252_Prevalance_of _PPROM_and_its_outcome/links/09e415113bcb9a046d000000.pdf

12. Patrick Duff, MD. Jun 16, 2016. Preterm premature (prelabor) rupture of membranes. UpToDate. Available: https://www.uptodate.com/contents/preterm-premature-prelabor-rupture-of-

membranes?source=search_result\&search=pprom\&selectedTitle=1 102\#H450397533 . (Accessed 2016-9-15)

13. Sonia Hernández-Díaz, Caroline E Boeke, Anna Thornton Romans, Brett Young,Andrea V. Margulis,Thomas F. McElrath, Jeffrey L. Ecker and Brian T. Bateman . Triggers of spontaneous preterm delivery - Why today?PaediatrPerinatEpidemiol. 2014 Mar; 28(2): 79-87. Published online 2014 Jan 2. Doi: 10.1111/ppe.12105 . Available : http://www.ncbi.nlm.nih.gov/pmc/articles/PMC4106670/ 
14. X. Xionga, L.D. Saunders, F.L. Wang, N.N. Demianczuk. Gestational diabetes mellitus: prevalence, risk factors, maternal and infant outcomes. International Journal of Gynecology \& Obstetrics. Volume 75, Issue 3, December 2001, Pages 221-228. Available http://www.sciencedirect.com/science/article/pii/S0020729201004969

15. D. GENE PARKS, MD and HARRY K. ZIEL, MD, FACOG. Macrosomia: A Proposed Indication for Primary Cesarean Section. Obstetrics \& Gynecology. October 1978 - Volume 52 - Issue 4. Available : http://journals.lww.com/greenjournal/Abstract/1978/10000/Macrosomia_A_Proposed_Indication_for_Primary .4.aspx

16. Posner AC, Friedman S, Posner LB. The large fetus: A study of 547 cases. Obstet Gynecol. 5:268 - 278.1955.

17. Nihal Al Riyami, Intisar Al-Ruheili, Fatma Al-Shezaw, and Murtadha Al-Khabori. Extreme Preterm Premature Rupture of Membranes: Risk Factors and Feto Maternal Outcomes. Oman Med J. 2013 Mar. v 28(2): 108-111. Available : http://www.ncbi.nlm.nih.gov/pmc/articles/PMC3628203/\#r10

18. David R. Doody, Matthew O, Patterson, Lvnda F. Voigt and Beth A. Mueller .Risk Factor For the recurrence of premature rupture of the membranes. Pediatric and Perinatal Epidemiology. 1997, 11, suppl. 1, 96-106. Available : http://onlinelibrary.wiley.com/doi/10.1046/j.1365-3016.11.s1.2.x/epdf

19. Abd-Alaziz A (MD). Maternal and Neonatal Outcomes of Delivery in Women with Preterm Prelabor Rupture of the Membranes (PPROM) A Retrospective Comparison between Deliveries after Versus Before 34 Weeks of Gestation.

International Journal of Obstetrics and Gynaecology Research (IJOGR). Vol. 2 (2015) No.4, pp. 199-207. http://www.ijogr.com/

20. Brian M. Mercer, MD, Lisa G. Crocker, RN, W. Frank Pierce, MD, Baha M. Sibai, MD. Clinical characteristics and outcome of twin gestation complicated by preterm premature rupture of the membranes. American Journal of Obstetrics and Gynecology. Volume 168, Issue 5, May 1993, Pages 1467-1473.

21. Mercer BM. The NICHD-MFMU antibiotic treatment of preterm PROM study: impact of initial amniotic fluid volume on pregnancy outcome. Am J Obstet Gynecol. 2006 Feb; 194(2):438-45.

22. Robert L. Andres, MD, Yuan Zhao, MS, Mark A. Klebanoff, MD, John C. Hauth, MD, Steve N. Caritis, MD, J. Christopher Carey, MD, Ronald J. Wapner, MD, Jay D. Iams, MD, Kenneth J. Leveno, MD, Menachem Miodovnik, MD, BahaSibai, MD, J. Peter Van Dorsten, MD, Mitchell P. Dombrowski, MD, Mary J. O'Sullivan, MD, and Oded Langer, MD . The Impact of Tobacco Use on Preterm Premature Rupture of the Membranes. Am J Perinatol. 2013 Mar; 30(3): 185-190. Available : http://www.ncbi.nlm.nih.gov/pmc/articles/PMC3962832/

23. David P. van der Ham, Sylvia M. C. Vijgen, Jan G. Nijhuis, Johannes J. van Beek,Brent C. Opmeer, Antonius L. M. Mulder, Rob Moonen, MariëtGroenewout, Mariëlle G. van Pampus, Gerald D. Mantel, Kitty W. M. Bloemenkamp, Wim J. van Wijngaarden, Marko Sikkema, Monique C. Haak, Paula J. M. Pernet, Martina Porath, Jan F. M. Molkenboer,SimoneKuppens, AnnekeKwee, Michael E. Kars, Mallory Woiski, Martin J. N. Weinans, Hajo I. J. Wildschut, Bettina M. C. Akerboom. Induction of Labor versus Expectant Management in Women with Preterm Prelabor Rupture of Membranes between 34 and 37 Weeks: A Randomized Controlled Trial. PLoS Med. 2012 Apr; 9(4): e1001208.

24. IngerAhlenius, Jan Floberg, Peter Thomassen. Sixty-six cases of intrauterine fetal death. ActaObstetriciaetGynecologicaScandinavica. Volume 74, Issue 2February 1995 .Pages 109-117. Available: http://onlinelibrary.wiley.com/doi/10.3109/00016349509008917/full [assessed 19-9-2016].

25. D.kaye, MBChB, MMed. Risk Factor for Preterm Premature Rupture of Membranes at Mulago Hospital, Kampala. East African Medical Journal. Vol.78 No.2 February 2001.

26. Nathanson JN. The excessively large fetus as an obstetric problem. Am J Obstet Gynecol. 60:54-63? 1950.

27. Courtney D Stephenson, DO, Charles J Lockwood, MD, MHCM , Andrew P MacKenzie, MD .Gastroschisis $\begin{array}{lllll}\text { Sep } & \text { 2016. } & \text {.UpToDate } & \text { Available }\end{array}$ :https://www.uptodate.com/contents/gastroschisis?source=search_result\&search=gastroschisis\&selectedTitle=1 $\sim 35$ [ Accessed 19-9-2016] 